\title{
Alkali-Silica Reactivity and Strength of Mortars with Expanded Slate, Expanded Glass or Perlite
}

\author{
Mehrzad Zahabi' ${ }^{1}$ Aly Said² \\ ${ }^{1}$ Design Engineer, McNamara Salvia Structural Engineers, Boston, MA, USA \\ ${ }^{2}$ Associate Professor, Department of Architectural Engineering, The Pennsylvania State University, University Park, PA, USA \\ Email: aly.said@engr.psu.edu
}

How to cite this paper: Zahabi, M. and Said, A. (2021) Alkali-Silica Reactivity and Strength of Mortars with Expanded Slate, Expanded Glass or Perlite. Open Journal of Civil Engineering, 11, 119-133.

https://doi.org/10.4236/ojce.2021.111008

Received: November 26, 2020

Accepted: March 14, 2021

Published: March 17, 2021

Copyright $\odot 2021$ by author(s) and Scientific Research Publishing Inc. This work is licensed under the Creative Commons Attribution International License (CC BY 4.0).

http://creativecommons.org/licenses/by/4.0/

\begin{abstract}
Lightweight aggregates are increasingly used in concrete construction. They reduce concrete selfweight furnishing a structural advantage. In contrast, the mechanical properties and durability of lightweight concrete can become the governing factor on lightweight aggregate replacement ratios. Alkali-Silica Reactison (ASR) and compressive strength of mortar samples with expanded slate, expanded glass or perlite, covering the spectrum of internal porosity and weight of lightweight aggregates, were evaluated. Scanning electron microscopy was utilized to evaluate the contribution of the aggregates' porosity and chemical composition in inhibiting ASR. Perlite, owing to its highly porous microstructure and lower matter excelled in ASR expansion while chemical composition and denser microstructure of the heavier expanded slate resulted in more signified late ASR expansion and higher compressive strength. An attempt in visual inspection of ASR attack of alkali metal ions on silica-rich expanded glass using an ultra-accelerated exposure to sodium hydroxide solution was made.
\end{abstract}

\section{Keywords}

Lightweight Concrete, Alkali-Silica Reaction, Expanded Glass Aggregate, Expanded Slate Aggregate, Perlite Aggregate

\section{Introduction}

Lightweight concrete (LWC) can be obtained either by utilization of aggregates with lighter densities or by partial bulk replacement of conventional normalweight concrete with lighter constituents. It can be explored for applications where heavy concrete weight is of concern or when thermal insulation or other properties need to be improved. It is used in floating or submerged offshore concrete structures as well due to more pronounced weight reduction of LWC 
(compared to normal-weight concrete) in water than in air [1]. Aggregates with densities less than $1100 \mathrm{~kg} / \mathrm{m}^{3}$ are typically considered lightweight. The light weight and low thermal conductivity are a result of porous microstructures of the aggregates (Figures 2-4) caused by heating raw materials to incipient fusion temperature, evolution of gasses in the pyroplastic mass expanding the microstructure, and formation of pores upon cooling [1]. The pores may also provide sites for internal water that is not part of the mixing water and hence potential for internal curing (IC). IC can reduce early-age shrinkage and increase concrete durability upon more uniform and longer time for the substantial segment of hydration [2].

Light-weight aggregates (LWA) with more uniformly distributed fine pores (between 5 to 300 micron) exhibit more potential for structural concrete [1] and can fully or partially be utilized. These aggregates with higher structural capacity can include expanded slate, shale or clay or expanded glass. The possible concrete strength loss by utilization of LWA is often retrieved to some extent by partial replacement of OPC with SCMs such as fly ash or slag. Reducing the maximum course LWA size can also elevate the strength and if needed, prestressed LWC with a strength of $70 \mathrm{MPa}$ or higher can be specified [1]. LWC by the virtue of its lower density has been utilized in military applications to dampen firearms and explosive blasts' energy transmitted by projectiles and fragments [1].

One recent application of lightweight aggregate was in Shasta Arch bridge project by Caltrans. Light-weight saturated Arcosa’s Hydrolite ${ }^{\circledR}$ expanded clay aggregate was used together with granulated blast-furnace slag (as partial replacement of $\mathrm{OPC}$ ) and air-entraining admixture. High-performance concrete with 56-day compressive strength of $42 \mathrm{MPa}$ was obtained while lowering the density from $2400 \mathrm{~kg} / \mathrm{m}^{3}$ for normal-weight concrete to $1900 \mathrm{~kg} / \mathrm{m}^{3}$. Few other case studies are available at the aggregate producer's website [3] while other applications from US producers of (denser) expanded shale, clay and slate are available. The Expanded Shale, Clay and Slate Institute (ESCSI) lists the US producer along with LWA documentations [4].

In this study, alkali-silica reactivity and mortar compressive strength of three light-weight aggregates, fine perlite, expanded slate and expanded glass were evaluated. ASR is a reaction between reactive silica in the aggregate and alkalis in the cement that results in progressive map (pattern) cracking in the concrete. ASTM C150 specifies cements with less than 0.6 percent equivalent $\mathrm{Na}_{2} \mathrm{O}$ as lowalkali and cements with more than 0.6 percent equivalent $\mathrm{Na}_{2} \mathrm{O}$ as high-alkali. This is due to the significant influence of the small presence of $\mathrm{Na}_{2} \mathrm{O}$ and $\mathrm{K}_{2} \mathrm{O}$ in the cement on $\mathrm{pH}$ of the pore fluid. It is suggested if total alkali content of concrete is less than $3 \mathrm{~kg} / \mathrm{m}^{3}$, the degree of ASR progress over time does not lead to undesirable expansions [5]. The hydroxyl ions present in the hydrated cement paste due to large amount of calcium hydroxide cause depolymerization/breakdown of silica (from aggregate) structure and the alkali-metal ions are absorbed 
into the surface of the breakdown products. Increasing supply of water to the produced alkali-silicate gel results in its swelling due to unconstrained buildup of hydraulic pressure and expansion/cracking of the aggregate and cement paste. The fracture progress eventually reaches the surface of the concrete concluding the pattern cracking. One strategy in mitigation of ASR is addition of supplementary cementing materials ( $\mathrm{SCMs}$ ) specially those high in alumina that are more readily available such as metakaolin. Despite high likelihood of its limited efficiency in reducing the alkalinity of concrete compared to usage of SCMs richer in silica, high-alumina SCMs mitigate the ASR progress. This is done by reduction of alkalinity of the pore solution through chemical composition alteration of calcium silicate hydrate phases and adsorption of alkali metal ions that cause higher adsorption of aluminum on the silica in the resulting low-alkalinity solution. The adsorbed aluminum contributes to lowering the intensity of the aggregate's silica attack by the alkali metal ions by suppressing dissolution of reactive silicates from the aggregates [6] [7].

This study helps furnish a better understanding of three light-weight aggregates to partially or fully replace normal-weight aggregates with potentials in applications where lightweight concrete is specified. Their microstructural pores can potentially house ASR gels, hindering deleterious expansions. Effect of a natural pozzolan and nano-silica in lowering ASR and potential improvement on the compressive strength was evaluated as well. Earlier studies show that nano-silica can have an impact on ASR [8] [9] [10]

\section{Experimental Details}

\subsection{Materials}

Three types of light-weight aggregates namely, expanded glass (brand name Poraver), fine perlite (Dicalite brand name Con-Agg) and expanded slate (brand name Stalite) were used in mortar compressive strength, ASR, and scanning electron microscopy (SEM) studies. Figure 1 illustrates the aggregates. Con-Agg perlite is at the low end of the weight spectrum [5] with minimal structural capacity if used solely as the aggregate in concrete. It is a result of its shell structure, resembling eggshell and predominantly submicron shell thickness, as shown in Figure 2. Stalite expanded slate (Figure 3), however, belongs to the higher end of the weight spectrum of light-weight aggregates. Weight of Poraver expanded glass (Figure 4) is between the two. Normal-weight reactive sand (NWRS) (reactive in terms of ASR) was used in this study for comparison purposes.

Utilizing Energy Dispersive X-Ray Spectroscopy (EDS), approximate chemical composition of the three light-weight aggregates are shown in Figures 5-7. All three are rich in silica but the high alkali metal oxides content of the expanded slate combined with its higher density (higher matter) compared to the other two make it more prone to ASR. It was expected that the ultra-porous perlite would easily accommodate ASR gels within its microstructure. 


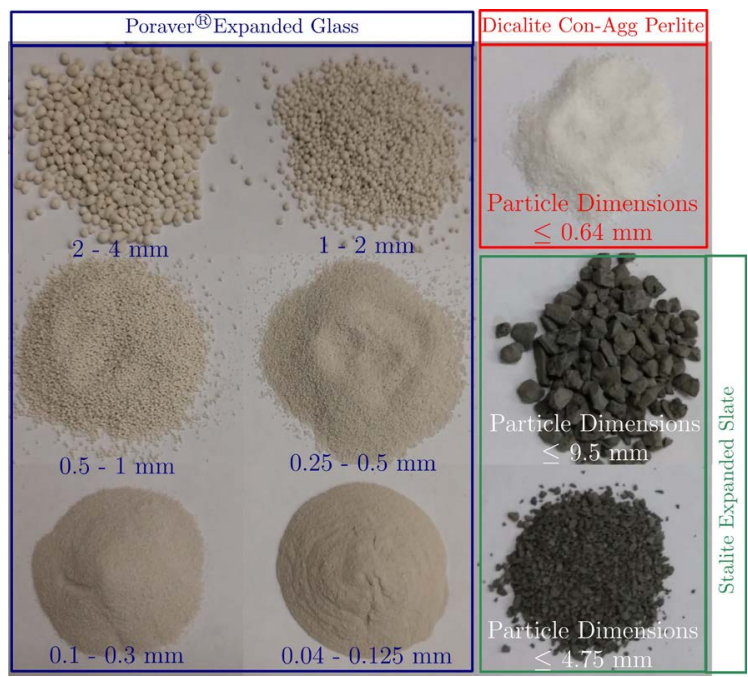

Figure 1. Particle sizes of three light-weight aggregate types.

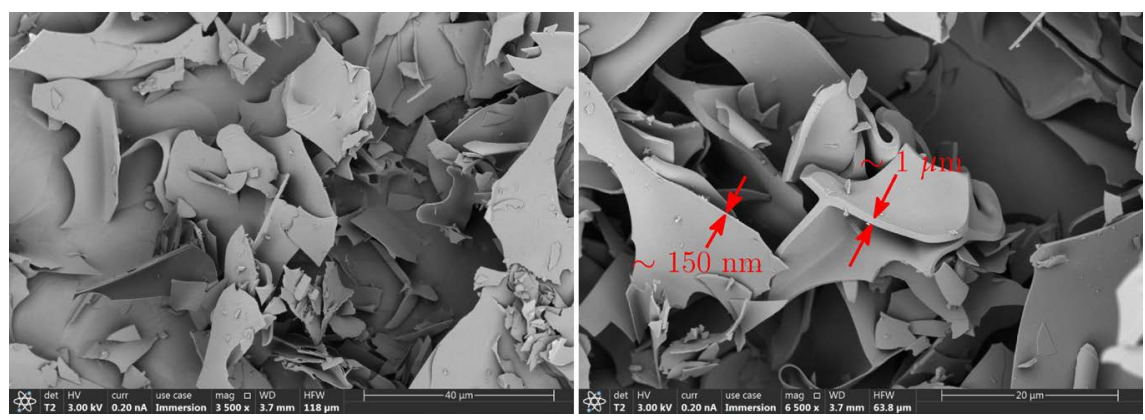

Figure 2. SEM images of fine perlite with fractured shells and submicron shell thickness.
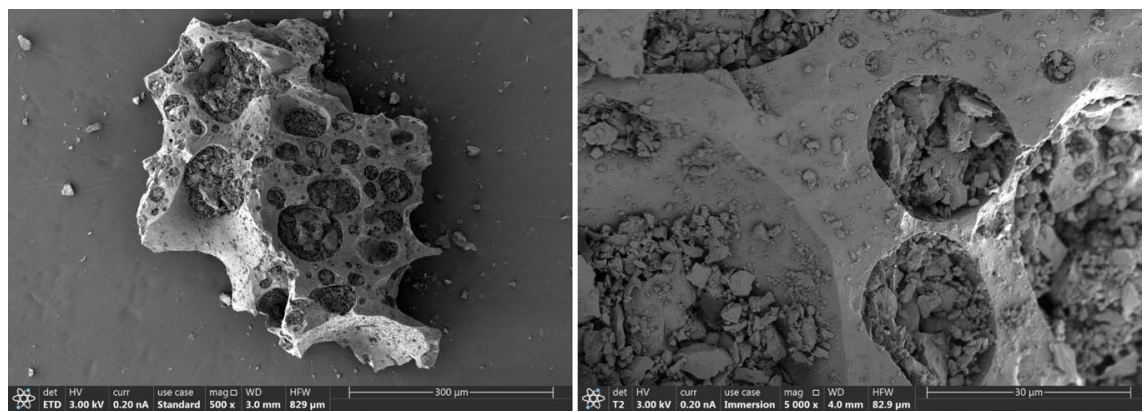

Figure 3. SEM images of expanded slate.
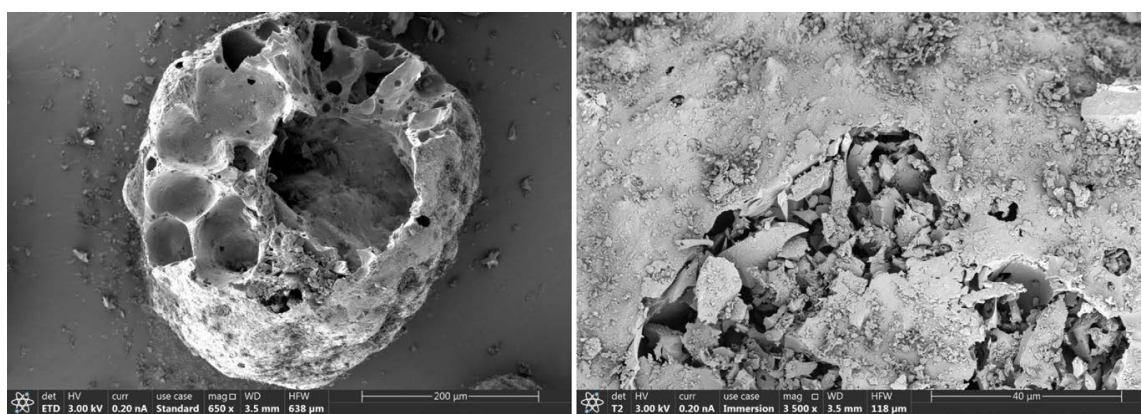

Figure 4. SEM images of expanded glass. 


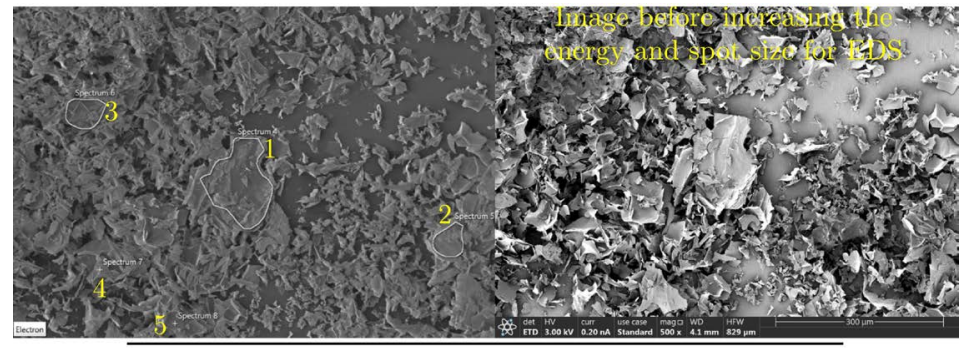

\begin{tabular}{cccccccc}
\hline \multicolumn{10}{c}{ Atomic Composition (Weight \%) } \\
\hline Zone/Point & $\mathrm{O}$ & $\mathrm{Na}$ & $\mathrm{Al}$ & $\mathrm{Si}$ & $\mathrm{K}$ & $\mathrm{Ca}$ & $\mathrm{Fe}$ \\
\hline 1 & 47.76 & 2.37 & 6.94 & 37.5 & 5.04 & 0.38 & \\
2 & 45.51 & 2.27 & 7.12 & 38.82 & 5.33 & 0.47 & 0.49 \\
3 & 39.87 & 1.9 & 7.5 & 42.63 & 7.45 & 0.66 & \\
4 & 56.5 & 1.23 & 6.56 & 33.76 & 1.6 & 0.35 & \\
5 & 40.23 & 28.86 & 4.69 & 22.8 & 3.16 & 0.26 & \\
\hline
\end{tabular}

Figure 5. Chemical composition of fine perlite.

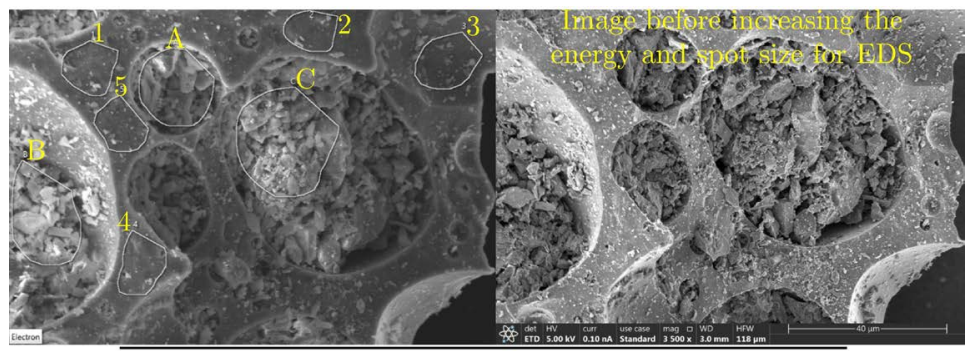

Atomic Composition (Weight \%)

\begin{tabular}{clccccccc}
\hline Zone & \multicolumn{1}{c}{$\mathrm{O}$} & $\mathrm{Na}$ & $\mathrm{Mg}$ & $\mathrm{Al}$ & $\mathrm{Si}$ & $\mathrm{K}$ & $\mathrm{Ca}$ & $\mathrm{Fe}$ \\
\hline 1 & 48.6 & 2.13 & 1.12 & 10.25 & 30.22 & 3.46 & & 4.22 \\
2 & 51.75 & 2.2 & 1.68 & 10.44 & 26.83 & 3.07 & & 4.03 \\
3 & 50.99 & 2.13 & 2.17 & 11.48 & 24.62 & 2.78 & & 5.82 \\
4 & 46.66 & 2.1 & 1.29 & 10.2 & 31.59 & 3.48 & & 4.69 \\
5 & 48.6 & 1.96 & 1.47 & 9.17 & 30.41 & 3.52 & & 4.87 \\
$\mathrm{~A}$ & 50.55 & 1.92 & 1.17 & 9.76 & 26.48 & 2.88 & 2.01 & 5.23 \\
$\mathrm{~B}$ & 50.5 & 2.18 & 1.35 & 9.77 & 25.23 & 2.97 & 1.88 & 6.12 \\
$\mathrm{C}$ & 50.93 & 2.14 & 1.24 & 10.51 & 25.86 & 3.53 & 1.07 & 4.73 \\
\hline
\end{tabular}

Figure 6. Chemical composition of expanded slate.

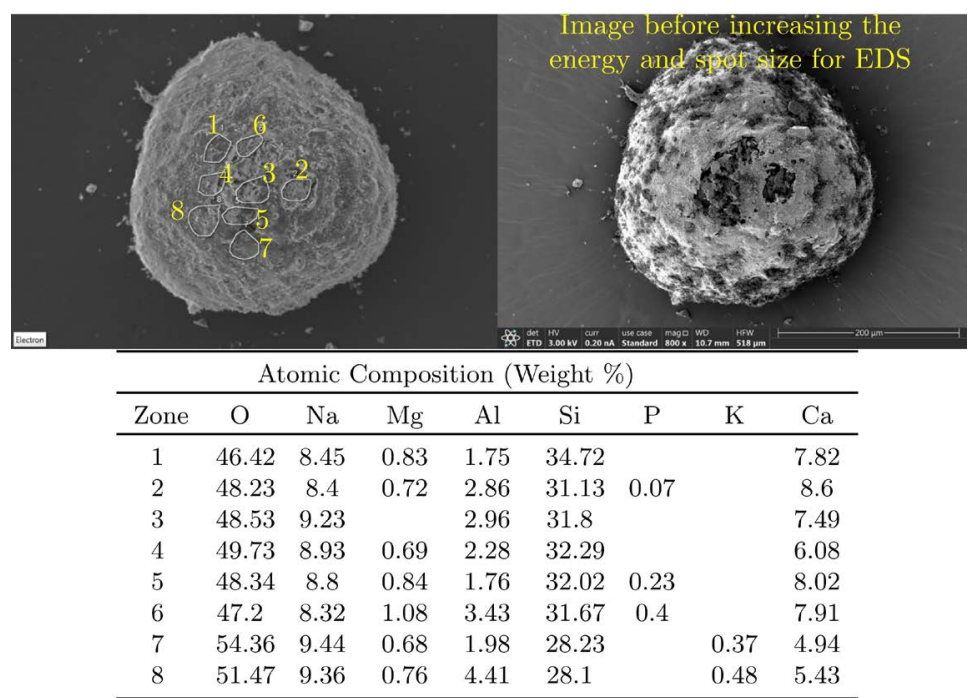

Figure 7. Chemical composition of expanded glass. 
Hydrophilic Aerosil 200 nano-silica (fumed silica) with BET surface area of $200 \mathrm{~m}^{2} / \mathrm{g}$ was used in the compressive strength and ASR studies. Generally, nano-silica is not as highly efficient as some of supplementary cementing materials (SCMs) in terms of enhancement of mechanical properties of conventional concrete but they excel in development of highly compact and durable concrete. They can nonetheless be supplied together with SCMs as partial replacement of ordinary cement to obtain high-performance concrete, furnishing strong and durable concretes [11] [12] [13]. Lassenite SR natural pozzolan (Table 1) was used in the ASR study.

Deionized (DI) water, polycarboxylate-based Sika Viscocrete 6100 superplasticizer (SP), where noted, and ordinary portland cement Type I were used throughout this study.

\subsection{Test Protocols}

\section{1) Accelerated Alkali-Silica Reaction}

Effects of chemical composition and pore microstructure of the three light-weight aggregates on ASR were evaluated by the accelerated mortar-bar method (ASTM C1567). Short-term ASR studied by exposure of the mortar bars to $1 \mathrm{M}$ aqueous solution of $\mathrm{NaOH}$ at $80^{\circ} \mathrm{C}$ (solution to mortar bar volumetric ratio was 4:1). Binder composed cement and supplementary cementing materials, if any. Mix water-to-binder mass ratio was 0.47 and sand particle size distribution for the normal-weight mortar bars was per ASTM C1567, providing sand-to-binder mass ratio of 2.25. Light-weight aggregate mortar bars mix proportions are shown in Table 2. Superplasticizer doses are shown in Figure 8.

\section{2) Ultra-Accelerated Alkali-Silica Reaction of Expanded Glass}

Three curing and exposure regimes of ultra-accelerated ASR of the expanded glass was followed in an effort to visually investigate early-age depolymerization mechanism of silica by hydroxyl ions and uptake of alkali-metal ions. Table 3 and Table 4 show the mix constituents and curing conditions, respectively. Expanded glass (250 micron $\leq$ particle size $\leq 500$ micron; Figure 1 ) was used as the only aggregate. Cement was added to a homogeneous mix of the aqueous solution and superplasticizer and mixed for 2 minutes at $400 \mathrm{rpm}$ using a high-shear mixer. Expanded glass was added and mixed at $800 \mathrm{rpm}$ for four minutes. Per Table 3, samples were first placed in sealed vials ( 7 milliliters per sample) at room temperature before placement in the curing solution. They were then cured in the solution after which their hydration was stopped by multiple isopropanol exchanges for two hours. Afterwards, SEM was conducted immediately.

\section{3) Mortar Cube Compressive Strength}

Compressive strengths of $50.8 \times 50.8 \times 50.8 \mathrm{~mm}^{3}$ cubic mortar specimens (ASTM C109) with the three grades of light-weight aggregate as full or partial replacement of the normal-weight sand were collected under load rate of 1.3 $\mathrm{kN} / \mathrm{sec}$. Table 5 shows the mix proportions and the densities. Superplasticizer 
was used to obtain workable mixtures as fine nano-silica clumps would reduce the mix workability if used without superplasticizer. "C", "A", "P" and " $S$ " in the mix labels refer to sample with the normal-weight angular sand, fine perlite, expanded glass and expanded slate as the primary aggregate, respectively.

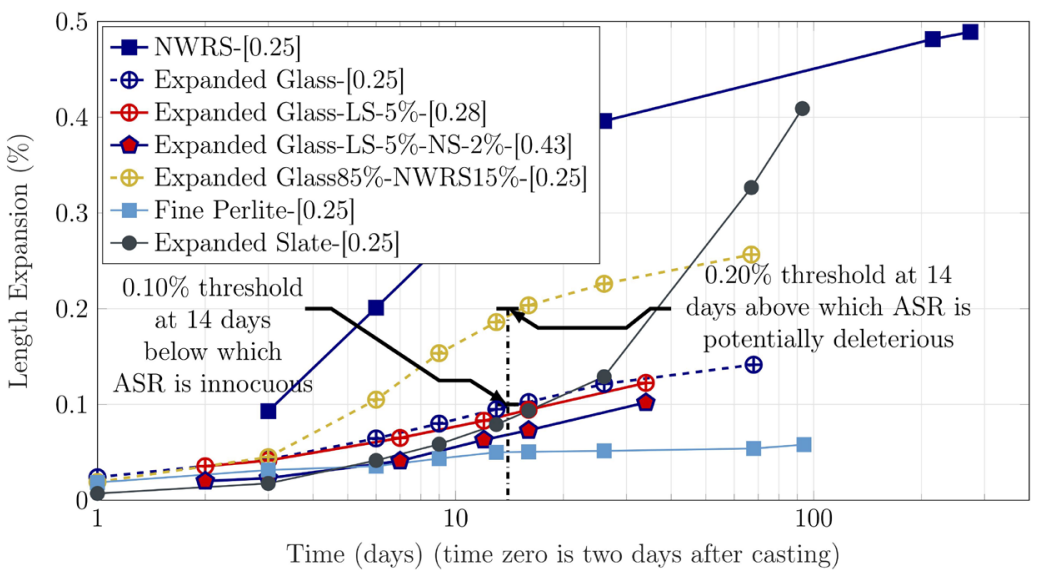

Figure 8. Alkali-silica reaction accelerated mortar bar test results of samples with light-weight aggregates. Natural pozzolan Lassenite SR (LS) and nano-silica (NS) were used as mineral admixtures. Numbers after the sample names in the legend refer to the replacement dose (\%) of mineral admixtures with respect to cement weight. Numbers in bracket refer to the percentage of superplasticizer dose with respect to binder (cement and mineral admixtures (if any)).

Table 1. Chemical compositions of Lassenite SR natural pozzolan (weight \%) (by X-ray fluorescence spectroscopy).

\begin{tabular}{cccccccccc}
\hline $\mathrm{SiO}_{2}$ & $\mathrm{Al}_{2} \mathrm{O}_{3}$ & $\mathrm{Na}_{2} \mathrm{O}$ & $\mathrm{K}_{2} \mathrm{O}$ & $\mathrm{MgO}$ & $\mathrm{Fe}_{2} \mathrm{O}_{3}$ & $\mathrm{CaO}$ & $\mathrm{TiO}_{2}$ & $\mathrm{MnO}_{2}$ & $\mathrm{P}_{2} \mathrm{O}_{5}$ \\
\hline 72.22 & 16.09 & 4.21 & 1.76 & 1.13 & 4.84 & 2.08 & 0.596 & 0.066 & 0.172 \\
\hline
\end{tabular}

Table 2. Mix proportions of control samples in ASR study of three light-wight aggregates.

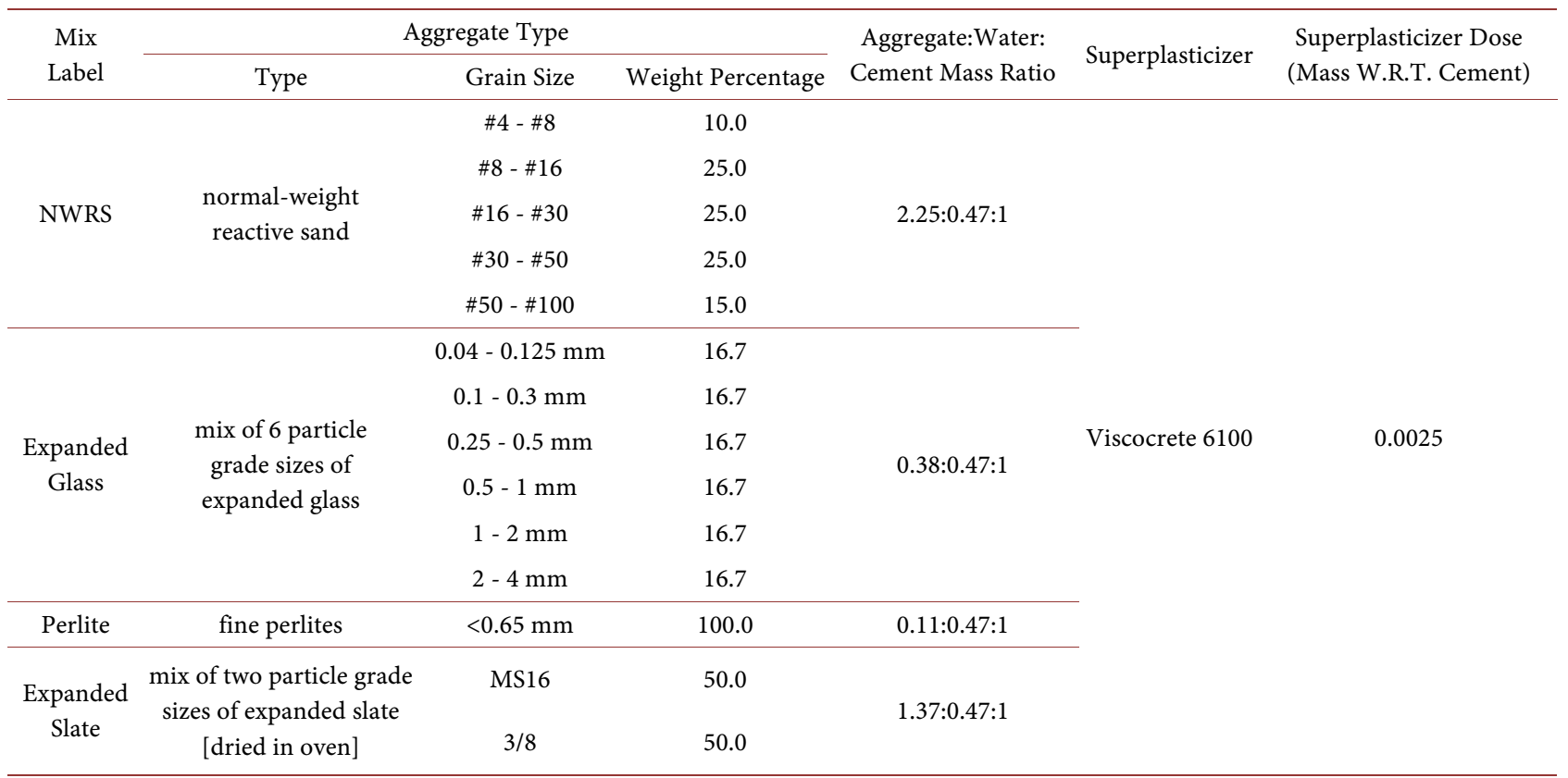


Table 3. Mix proportions of ultra-accelerated ASR samples using expanded glass as the aggregate. Ratios are in terms of mass with respect to cement.

\begin{tabular}{|c|c|c|c|c|c|c|}
\hline \multirow{3}{*}{ Label } & \multicolumn{6}{|c|}{ Mix Constituents } \\
\hline & \multicolumn{2}{|c|}{ Aqueous Solution } & \multicolumn{2}{|c|}{ Aggregate } & \multirow{2}{*}{$\begin{array}{c}\text { Cement } \\
\text { Ratio }\end{array}$} & \multirow{2}{*}{$\frac{\text { Superplasticizer }}{\text { Ratio }}$} \\
\hline & $\mathrm{NaOH}[20 \mathrm{M}]$ Ratio & DI Water Ratio & Type & Ratio & & \\
\hline U1 & 0.376 & 0.47 & Expanded Glass & 0.38 & 1.0 & 0.0025 \\
\hline $\begin{array}{c}\mathrm{U} 2 \\
\mathrm{U} 2-\mathrm{Ca}(\mathrm{OH})_{2}\end{array}$ & 0 & 0.47 & Expanded Glass & 0.38 & 1.0 & 0.0025 \\
\hline
\end{tabular}

Table 4. Curing conditions for ultra-accelerated ASR samples using expanded glass as the aggregate. Volume for each sample placed in the curing solution was 7 milliliters.

\begin{tabular}{ccccc}
\hline & & \multicolumn{2}{c}{ Curing Solution and Duration } \\
Label & $\begin{array}{c}\text { Sample Curing Time Before } \\
\text { Placement in Curing Solution (Hours) }\end{array}$ & \multicolumn{2}{c}{ Composition } \\
\cline { 3 - 5 } & 20 & NaOH $[20 \mathrm{M}]$ (gram) & $\mathrm{DI} \mathrm{Water} \mathrm{(gram)} \mathrm{Ca}(\mathrm{OH})_{2}(\mathrm{gram})$ \\
$\mathrm{U} 1$ & 20 & 24 & 30 & 30 \\
$\mathrm{U} 2-\mathrm{Ca}(\mathrm{OH})_{2}$ & 20 & 24 & 0 & 30 \\
\hline
\end{tabular}

Table 5. Mix proportions of mortar compressive strength study with three light-wight aggregates.

\begin{tabular}{|c|c|c|c|c|c|c|c|}
\hline $\begin{array}{l}\text { Mix } \\
\text { Label }\end{array}$ & $\begin{array}{c}\text { Mortar } \\
\text { Density } \\
\left(\mathrm{gram} / \mathrm{cm}^{3}\right)\end{array}$ & Aggregate Type & $\begin{array}{l}\text { Aggregate:Water: } \\
\text { Cement Mass Ratio }\end{array}$ & Superplasticizer & $\begin{array}{l}\text { Superplasticizer Dose } \\
\text { (Mass W.R.T. Cement) }\end{array}$ & Nanomaterial & $\begin{array}{c}\text { Nanomaterial Dose } \\
\text { (Mass Ratio W.R.T. } \\
\text { Cement) }\end{array}$ \\
\hline $\mathrm{C} 1$ & 2.36 & & $2.75: 0.485: 1$ & - & - & - & - \\
\hline $\mathrm{C} 2$ & 2.36 & NWRS & $2.75: 0.485: 1$ & & 0.0010 & & 0.015 \\
\hline $\mathrm{C} 3$ & 2.36 & & $2.75: 0.485: 1$ & & 0.0010 & & 0.045 \\
\hline A1 & 1.53 & & $0.18: 0.485: 1$ & & 0.0010 & & \\
\hline A2 & 1.19 & fine perlites & $0.3: 0.485: 1$ & & 0.0050 & & \\
\hline A3 & 1.29 & & $0.3: 0.3: 1$ & & 0.0225 & & \\
\hline A4 & 1.66 & $\begin{array}{l}\text { fine perlites (50 wt\%) } \\
+ \text { NWRS (50 wt } \%)\end{array}$ & $0.3: 0.485: 1$ & & 0.0075 & & \\
\hline A5 & 170 & fine perlites ( $25 \mathrm{wt} \%$ ) & $0.3: 0.485: 1$ & & 0.0050 & & \\
\hline A6 & 1.70 & + NWRS (75 wt\%) & $0.3: 0.485: 1$ & & 0.0025 & & \\
\hline $\mathrm{P} 1$ & 1.14 & $\begin{array}{l}\text { equal mix of } 6 \text { particle } \\
\text { grade sizes of }\end{array}$ & $0.6: 0.485: 1$ & & 0.0050 & & \\
\hline P2 & 1.21 & expanded glass & $0.6: 0.3: 1$ & Viscocrete 6100 & 0.0100 & $\begin{array}{l}\text { Nano-silica } \\
\text { Aerosi } 1^{\oplus} 200\end{array}$ & \\
\hline $\mathrm{P} 3$ & 1.50 & $\begin{array}{l}\text { equal mix of } 6 \text { particle } \\
\text { grade sizes of expanded } \\
\text { glass }(50 \mathrm{wt} \%)+ \\
\text { NWRS }(50 \mathrm{wt} \%)\end{array}$ & $0.6: 0.485: 1$ & & 0.0050 & Aerosil 200 & 0.015 \\
\hline P4 & 127 & $\begin{array}{l}\text { equal mix of } 6 \text { particle } \\
\text { grade sizes of expanded }\end{array}$ & $0.6: 0.485: 1$ & & 0.0050 & & \\
\hline P5 & 1.27 & $\begin{array}{l}\text { glass }(75 \text { wt } \%)+ \\
\text { NWRS }(25 \text { wt } \%)\end{array}$ & $0.6: 0.485: 1$ & & 0.0025 & & \\
\hline S1 & 1.84 & $\begin{array}{l}\text { equal mix of two } \\
\text { particle grade sizes } \\
\text { (MS16 fines and 3/8) }\end{array}$ & $1.92: 0.485: 1$ & & 0.0050 & & \\
\hline S2 & 1.78 & $\begin{array}{l}\text { of expanded slate } \\
\text { (dried in oven) }\end{array}$ & $1.92: 0.3: 1$ & & 0.0100 & & \\
\hline
\end{tabular}




\section{Results and Discussion}

\subsection{Alkali-Silica Reaction}

Light-weight aggregates are often reported beneficial in mitigation or reduction of ASR. This contribution is through their lighter density (lower matter available to the cement paste's alkali content to react with), higher porosity, higher water absorption within the pores diffusing alkali ions away from the reactive aggregates, and potentially pozzolanic behavior if sufficiently small aggregates are used and their composition is suitable [14] [15]. Among the light-weight mortars of this study, the mortar bar with expanded glass exhibited the highest potential for early-age ASR among the three samples with the light-weight aggregate as the only aggregate and with no mineral admixtures, as shown in Figure 8. This sample's expansion was, however, lower than the early-age ASR expansion of the control mortar bar with the NWRS. ASR expansion of the expanded glass is a result of the expanded glass' high alkali oxides, silica and lime contents, facilitating complexation of the its silica with alkali ions of cement pore solution. Similar synergistic deleterious effect of high alkalinity of expanded glass (through depletion of alkali ions into the pore solutions) and its high silica content is reported in literature [16]. The sample's 16-day (after sample casting; 14-day expansion on the plot) expansion of $0.1025 \%$ is close to $0.10 \%$ threshold to be classified as innocuous by ASTM C1260. Although some of the ASR gel was accommodated within the light-weight aggregates' internal pores and void contents as low as 3\%-7\% are reported beneficial in dampening of ASR expansion [14] [16], spalling of the mortar bar in the sample with the expanded glass was observed after 68 days in the $\mathrm{NaOH}$ solution. This took place where coarser aggregates were present (Figure 9). This is attributed to a combination of 1) more available alkali oxides and silica in coarser aggregates for the alkali ions in the cement pore solution and the aggregates' inability to accommodate the ASR gel within their pores, 2) larger pre-existing pores within the coarser aggregates introduced in the glass recycling or expansion production stages, intensifying the rate of fracture energy release followed by crack extension and concrete expansion that further provided the pore alkali ions with higher silica-rich sites within the aggregate to generate ASR gels, and 3) high pozzolanic activity of the aggregate, generating dense C-S-H hydrates and therefore, pressure buildup by formation of ASR gels, as discussed in literature [17]. Figure 10 illustrates early-age images of the mortar sample not exposed to $\mathrm{NaOH}$ solution.

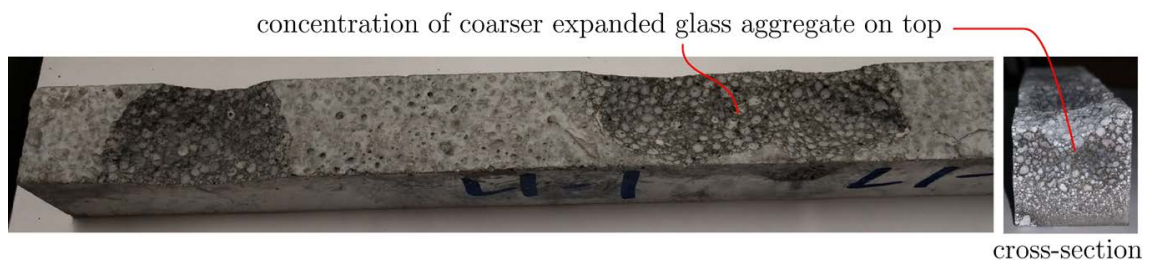

Figure 9. Spalling of the mortar bar in the sample with expanded glass where coarser aggregates are present. Sample was exposed to $1 \mathrm{M} \mathrm{NaOH}$ solution for 68 days. 


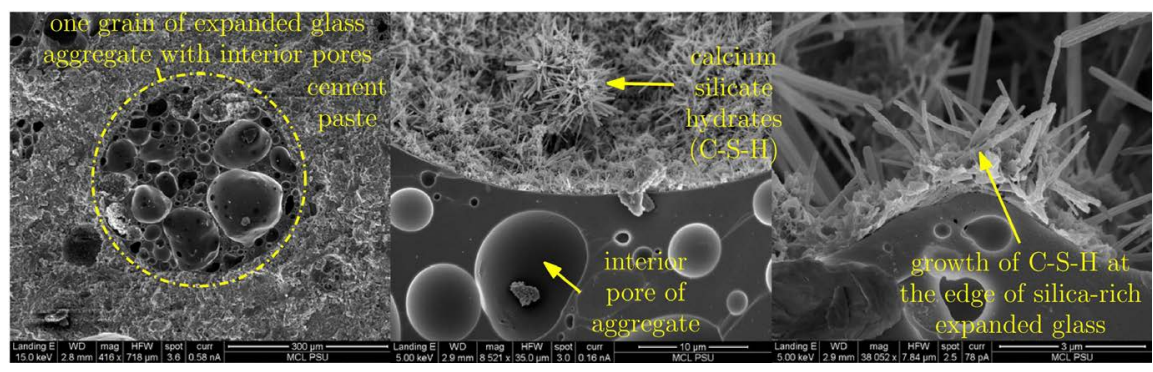

Figure 10. SEM images of OPC mortar with expanded glass as the aggregate. Sample age was 48 hours and aggregate:water:cement weight ratio was 0.38:0.47:1.

It is shown that replacement of the expanded glass with the normal-weight reactive sand by 15 weight percent (comparatively lower volumetric replacement percentage) can elevate the early-age expansion to $0.20 \%$ at 16 days, making it potentially deleterious per ASTM standard. A small dose (5 wt\%) of Lassenite SR is shown to be effective in dampening the ASR reactivity of the expanded glass. This is caused largely by the moderate presence of alumina content in the natural pozzolan and a higher replacement dosage would have reduced the expansion further. Combining the natural pozzolan with nano-silica can further lower the ASR potential of mortar bars with the expanded glass or NWRS. NS, owing to its ultra-high surface area can potentially provide more nucleation sites for the cement pore alkali ions, and lowering the alkalinity, facilitate adsorption of the natural pozzolan's aluminum into the surface of the aggregate silicate phases, lowering ASR expansion. The desirable effect of $2 \%$ nano-silica in the addition to $5 \%$ of the natural pozzolan is shown in the figure.

The mortar bars with fine perlite and expanded slate show $0.05 \%$ and $0.094 \%$ expansions at 16 days, respectively, and are considered harmless. Although silica content and alkalinity of the perlite is high to hypothetically propel ASR expansion based on literature reports [16], the ultra-low expansion of the mortar bar with perlite was caused by accommodation of ASR gels within the aggregate's highly porous microstructure (Figure 2) and its very low solid content compared to the other two light-weight aggregates. Growth of the cement hydration products within the aggregate's pores is shown in Figure 11 in a sample not exposed to $\mathrm{NaOH}$ solution. Perlite of similar density/porosity can, therefore, be utilized to replace normal-weight reactive aggregates at sufficiently small ratios to mitigate ASR and yet retain acceptable mechanical properties.

The sample with expanded slate showed high expansion tendency at later ages. This slow ASR progress is attributed mostly to its less porous microstructure and higher density although the aggregate's silica content and alkalinity play major roles. Similar early-age (14-day) expansion of less than $0.1 \%$ is reported in literature where pre-wetting of the expanded slate increased the ASR expansion [18]. The slow long-term ASR expansion of concrete with these dense expanded slate aggregates, however, needs further investigation and likely, require mitigation strategies. Figure 12 shows the cement hydrates filling the pores in a sample 


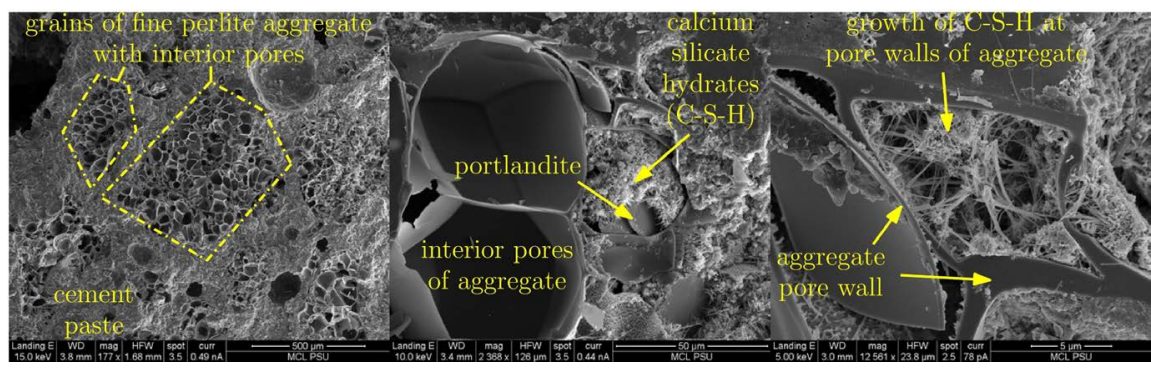

Figure 11. SEM images of OPC mortar with fine perlite as a light-weight aggregate. Sample age was 48 hours and aggregate:water:cement weight ratio was 0.11:0.47:1.

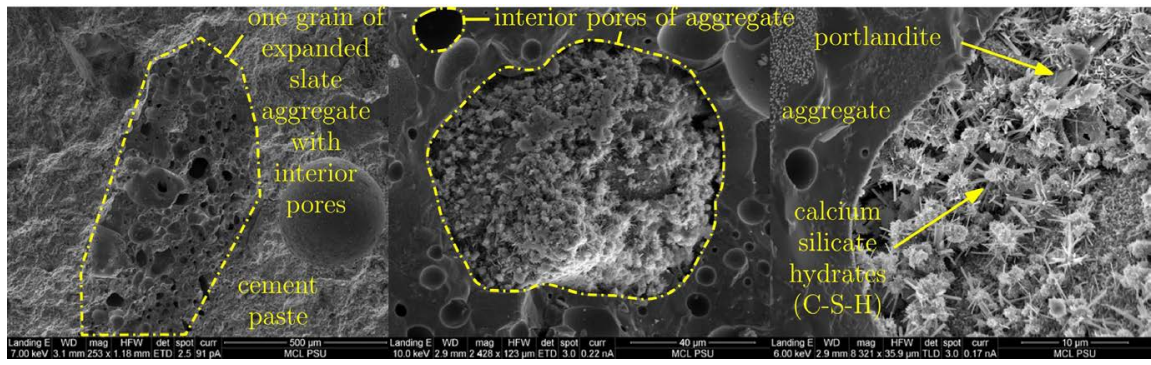

Figure 12. SEM images of OPC mortar with expanded slate as the aggregate. Sample age was 48 hours and aggregate:water:cement weight ratio was 1.37:0.47:1.

with expanded slate as aggregate that was not exposed to $\mathrm{NaOH}$ solution. In all light-weight concrete prone to ASR, supplementary cementing materials such as nano-silica and natural pozzolans can be specified to significantly reduce the expansion.

\subsection{Ultra-Accelerated Alkali-Silica Reaction of Expanded Glass}

Aggressive attack of sodium ions on the surface of the expanded glass grains of sample U1 (Table 3) is shown in Figure 13, leaving behind a large number of pores upon removal of small balls of glass and calcium (sodium) silicate hydrate (C-N-S-H). This sample had a significantly lower strength compared to samples $\mathrm{U} 2$ and $\mathrm{U} 2-\mathrm{Ca}(\mathrm{OH})_{2}$ due to large presence of sodium hydroxide within the cement paste during sample preparation. The low strength is attributed to the flower/honeycomb-shaped form of the C-N-S-H and highly attacked/porous expanded glass aggregates, forming a large number of pores and porous needles on the glass surface, shown in the figure. Sample U1 submerged quickly after placement in the curing solution. This was another indication of the aggressive attack and the large number of pores, facilitating update of the curing solution within the pores and submersion of the paste. In contrast, it took several hours for the other two samples to submerge in their curing solutions. Figure 14 illustrates the ASR attack on sample U2 with DI water as the mixing medium followed by exposure to high-molarity $\mathrm{NaOH}$ solution. Small glass and C-N-S-H balls were formed and popped out by the attack from the glass surface, but the extent of attack was significantly less than that of sample U1. Similar flower/ honeycomb-shaped form of the C-N-S-H was observed, some of which grew 
fully or partially within the glass grain.

Curing of sample $\mathrm{U} 2-\mathrm{Ca}(\mathrm{OH})_{2}$ for 6 hours in the $\mathrm{NaOH}$ solution that carried saturated $\mathrm{Ca}(\mathrm{OH})_{2}$ appears to have formed more spongy C-N-S-H, compared to samples $\mathrm{U} 1$ and $\mathrm{U} 2$, by complexation of more abundant $\mathrm{Ca}(\mathrm{OH})_{2}$ with the glass, as shown in Figure 15. The spongy C-S-H resembles that of the unexposed sample (Figure 10) the most among the samples exposed to the accelerated ASR regimes and potentially, a reason for higher strength of sample $\mathrm{U} 2-\mathrm{Ca}(\mathrm{OH})_{2}$ among the three samples.

\subsection{Mortar Cube Compressive Strength}

Figure 16, Figure 17 show mortar compressive strength and density results of light-weight mortar samples. They demonstrate two exemplifying strategies to obtain lighter concrete by either full replacement of the normal-weight aggregate by more compact variations of light-weight aggregates such as expanded slate (Sample S1) or by partial replacement of the normal-weight aggregate by ultra-light fine perlite (Sample A6). The former showcased 15\% strength reduction and $22 \%$ density reduction compared to the control sample while the latter presented $65 \%$ strength reduction and $28 \%$ density reduction. This trend can be further studied and optimized in concrete with coarser expanded slate, clay or shale or with partial replacement of normal-weight aggregates with those at the

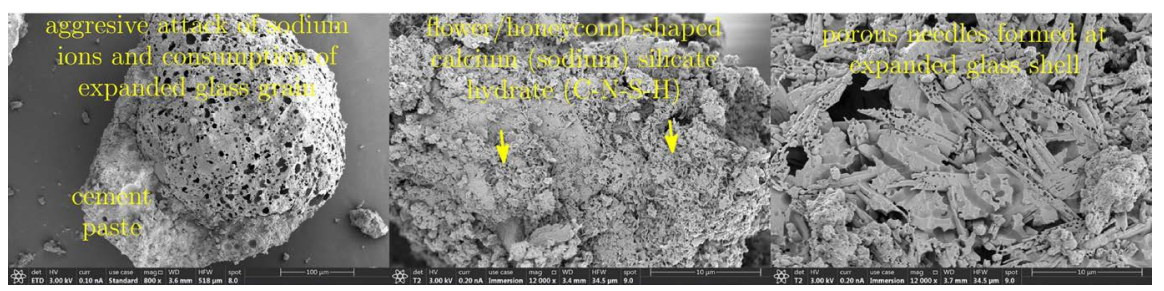

Figure 13. SEM images of 26-hour mortar with expanded glass as aggregate and 20M $\mathrm{NaOH}$ aqueous solution mixed with cement as the binder (sample U1 in Table 3) exposed to ultra-accelerated ASR regime.

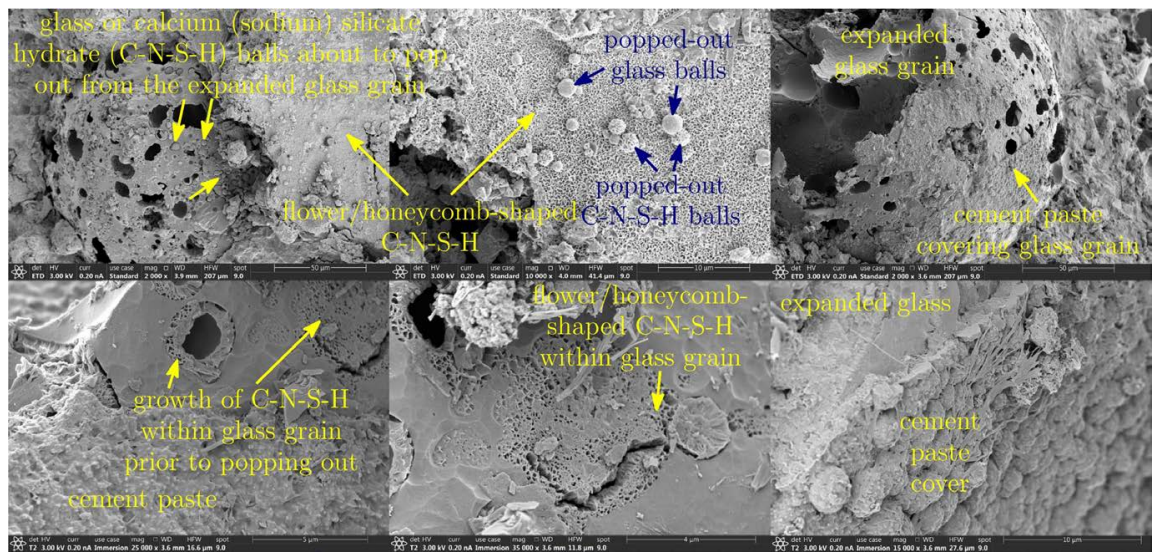

Figure 14. SEM images of 26-hour mortar with expanded glass as aggregate and DI water mixed with cement as the binder (sample U2 in Table 3) exposed to ultra-accelerated ASR regime. 


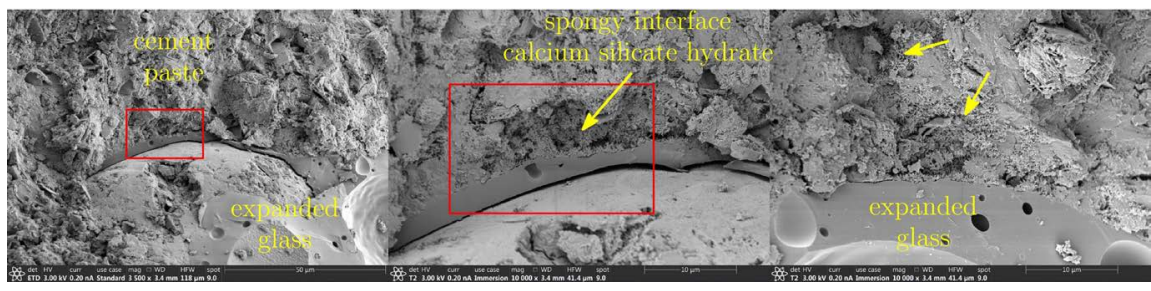

Figure 15. SEM images of 26-hour mortar with expanded glass as aggregate and DI water mixed with cement as the binder (sample $\mathrm{U} 2-\mathrm{Ca}(\mathrm{OH})_{2}$ in Table 3) exposed to ultra-accelerated ASR regime with solution that contained saturated $\mathrm{Ca}(\mathrm{OH})_{2}$.

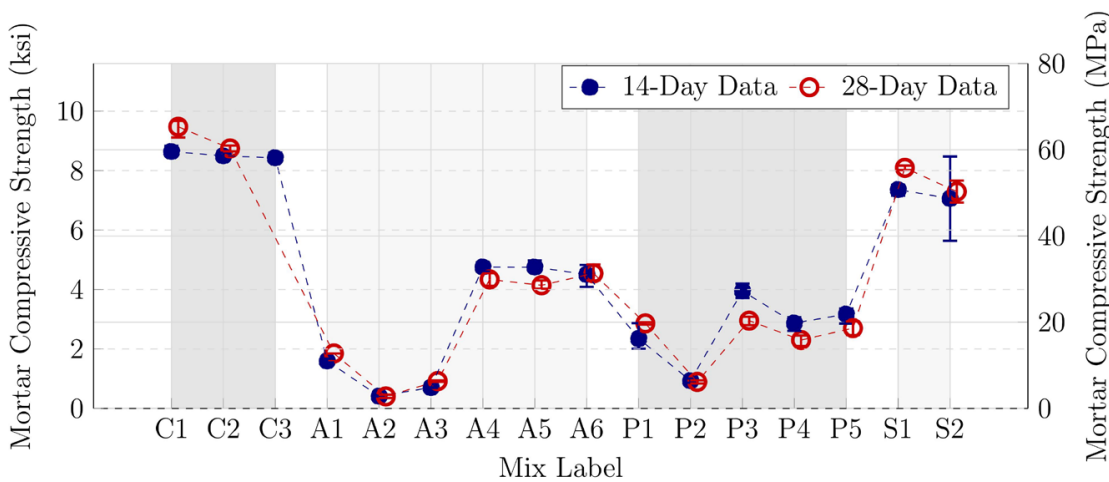

Figure 16. Results of compressive strength (ASTM C109) of mortar specimens with light-weight aggregates as full or partial replacement of normal-weight aggregate (sand). Load rate: $1.3 \mathrm{kN} / \mathrm{sec}$. All samples (except S2 and A6) had very small standard deviation among their three tested samples, as shown by the narrow error bars.

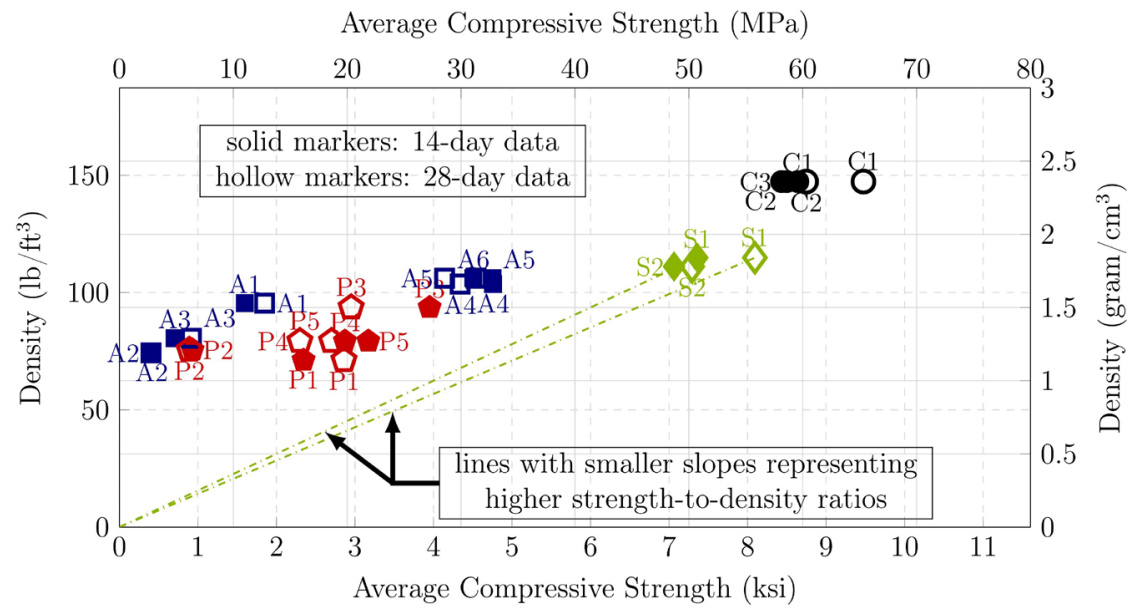

Figure 17. Density vs average compressive strength of mortar specimens with light-weight aggregates as full or partial replacement of normal-weight aggregate (sand).

lower end of the weight spectrum. Samples with the expanded glass exhibited relatively low strengths when used as the only aggregated. Interestingly, their strength at 28 days reduced compared to the strength at 14 days. This is believed to be caused by the large aggregate pores particularly in coarse aggregates that upon growth of the cement hydrates (further assisted by supplementation of nano-silica) and potentially, slight production of alkali-silica expansion (due to 
the aggregate's high alkali oxides and lime content), resulted in pressure builtup and formation of a higher number of micro-cracks at 28 days. Another possibility is inhomogeneous distribution of particles by separation of the coarser (lighter) aggregates, floating on top layer of the samples. A narrow and fine aggregate particle size distribution would have enhanced the strengths.

Nano-silica does not show improvement in the strength of control specimen and the change between $\mathrm{C} 1$ and $\mathrm{C} 2$ results could be within experimental errors. Nano-silica however outdoes in durability properties and can be studied further with variations of lightweight concrete.

\section{Conclusions}

Effect of porosity extent and chemical composition of three aggregates covering the full weight spectrum of light-weight aggregates on mortar ASR and compressive strength was studied. Ultra-light perlite, owing to its highly porous microstructure and very low density showed a very low tendency for ASR expansion. It was shown its partial replacement of normal-weight sand at high volumetric ratios can still retain acceptable strengths. This is particularly beneficial considering the aggregate's low ASR potential but durability properties of the aggregate need further studies.

Mortar samples with expanded slate showed the highest strength among the light-weight samples and favorable strength-to-density when compared to samples with normal-weight sand. This illustrates its potential as the sole aggregate for structural application but its potentially high ASR expansion needs to be controlled by supplementary cementing materials and/or inclusion of sufficiently high content of non-reactive aggregates into the concrete mixture. Long-term ASR behavior of expanded slate using such tests as ASTM C1293 needs further investigation.

Coarser aggregates of expanded glass exhibited higher ASR susceptibility compared to smaller aggregates. Their ASR mitigation and strength can be improved by utilization of supplementary cementing materials and supplementation with normal-weight aggregates.

\section{Conflicts of Interest}

The authors declare no conflicts of interest regarding the publication of this paper.

\section{References}

[1] ACI Committee 213 (2014) Guide for Structural Lightweight-Aggregate Concrete. American Concrete Institute.

[2] Weiss, J., Schindler, A.P.E., Lura, P. and Bentz, D. (2012) Internal Curing-Constructing More Robust Concrete. Structure Magazine, 10-14.

[3] Arcosa Lightweight (2019) Arcosa Lightweight Case Studies. https://www.arcosalightweight.com/case-studies 
[4] ESCSI (2019) The Expanded Shale, Clay and Slate Institute. https://www.escsi.org/memberlist/

[5] Mehta, P.K. and Monteiro, P.J. (2014) Concrete: Microstructure, Properties, and Materials.

[6] Chappex, T. and Scrivener, K. (2012) Alkali Fixation of C-S-H in Blended Cement Pastes and Its Relation to Alkali Silica Reaction. Cement and Concrete Research, 42, 1049-1054. https://doi.org/10.1016/j.cemconres.2012.03.010

[7] Chappex, T. and Scrivener, K.L. (2012) The Influence of Aluminium on the Dissolution of Amorphous Silica and Its Relation to Alkali Silica Reaction. Cement and Concrete Research, 42, 1645-1649. https://doi.org/10.1016/j.cemconres.2012.09.009

[8] Zeidan, M. and Said, A.M. (2017) Effect of Colloidal Nano-Silica on Alkali-Silica Mitigation. Journal of Sustainable Cement-Based Materials, 6, 126-138. https://doi.org/10.1080/21650373.2016.1191387

[9] Zeidan, M. and Said, A. (2015) Alkali-Silica Reaction Mitigation Using Nano-Silica and Fly Ash in Nanotechnology in Construction. Springer, Cham, 459-464. https://doi.org/10.1007/978-3-319-17088-6 60

[10] Said, A.M., Islam, M.S., Zeidan, M.S. and Mahgoub, M. (2020) Effect of Nano-Silica on the Properties of Concrete and Its Interaction with Slag. Transportation Research Record, 0361198120943196. https://doi.org/10.1177/0361198120943196

[11] Ayad, A. and Said, A. (2018) Using Colloidal Nano Silica to Enhance the Performance of Cementitious Mortars. Open Journal of Civil Engineering, 8, 82-90. https://doi.org/10.4236/ojce.2018.81007

[12] Said, A. M., and Zeidan, M. S. (2009) Enhancing the reactivity of normal and fly ash concrete using colloidal nano-silica. Special Publication, 267, 75-86.

[13] Zeidan, M., Bassuoni, M. T. and Said, A. (2017) Physical Salt Attack on Concrete Incorporating Nano-Silica. Journal of Sustainable Cement-Based Materials, 6, 195216. https://doi.org/10.1080/21650373.2016.1218802

[14] Collins, R.J. and Bareham, P.D. (1987) Alkali-Silica Reaction: Suppression of Expansion Using Porous Aggregate. Cement and Concrete Research, 17, 89-96. https://doi.org/10.1016/0008-8846(87)90063-9

[15] Dahl, P.A., Justnes, H., Norden, G. and Hyrve, O. (2007) Lightweight Aggregate Fines as Pozzolanic Additive for High-Performance Concrete. Special Publication, 242, 333-350.

[16] Mladenovič, A., Šuput, J.S., Ducman, V. and Škapin, A.S. (2004) Alkali-Silica Reactivity of Some Frequently Used Lightweight Aggregates. Cement and Concrete Research, 34, 1809-1816. https://doi.org/10.1016/j.cemconres.2004.01.017

[17] Rajabipour, F., Maraghechi, H. and Fischer, G. (2010) Investigating the Alkali-Silica Reaction of Recycled Glass Aggregates in Concrete Materials. Journal of Materials in Civil Engineering, 22, 1201-1208. https://doi.org/10.1061/(ASCE)MT.1943-5533.0000126

[18] Li, C., Thomas, M.D. and Ideker, J.H. (2018) A Mechanistic Study on Mitigation of Alkali-Silica Reaction by Fine Lightweight Aggregates. Cement and Concrete Research, 104, 13-24. https://doi.org/10.1016/j.cemconres.2017.10.006 